\title{
Distribution and significance of nitrogen isotopic compositions of bulk rock and kerogen within organic matter rich fine-grained sedimentary rocks of continental lacustrine basins
}

\author{
JIANFA CHEN $^{1}$, JUAN CHEN ${ }^{1}$, SHENGBAO SHI ${ }^{1}$
}

${ }^{1}$ State Key Laboratory of Petroleum Resources and

Prospecting, China University Petroleum Beijing, Fuxue

Road 18, Changping, Beijing 102249, China

Application of Molecular Geochemistry to Paleoenvironmental Reconstruction Across Timescales

The nitrogen isotopic compositions of sedimentary rocks can be used to investigate ancient sedimentary environments, the nitrogen biogeochemical cycle and thermal evolution degree. Bulk rock is typically as the analysis object for organic nitrogen isotope research in sedimentary rocks. However, nitrogen is contained in sedimentary rocks in two different phases: organic nitrogen (bound to organic carbon) and inorganic nitrogen (ammonium substituted in silicate), indicating that it is important to understand whether $\delta^{15} \mathrm{~N}_{\text {bulk }}$ can adequately reflect the nitrogen isotopic compositions of organic matter within these sediments. To address this question, we measured nitrogen isotopic, carbon isotopic and total organic carbon (TOC) values for fine-grained sedimentary rocks of the Triassic Yanchang Formation (YF) from the Ordos Basin and the Cretaceous Qingshankou Formation (QF) from the Songliao Basin, the two largest terrestrial lacustrine basins in China. The results reveal that organic matter rich sedimentary rock from YF and QF have lower $\delta^{15} \mathrm{~N}_{\text {bulk }}$ values than their $\delta^{15} \mathrm{~N}_{\mathrm{ker}}$ (i.e., kerogen nitrogen isotope) values. Thermal evolution (vitrinite reflectance Ro range from $0.7 \%$ to $1.3 \%$ ) does not significantly modify the nitrogen isotopic composition of bulk rock and kerogen. A comparison of nitrogen isotopic composition for the sedimentary rock from YF and QF indicates that $\delta^{15} \mathrm{~N}_{\text {bulk }}$ values can be used as a proxy for organic nitrogen isotope characteristics in fine-grained sedimentary rock with TON/TN (i.e., total organic nitrogen/total nitrogen) values of $>0.4$, but not for samples with TON/TN values of $<0.4$. During early diagenesis, denitrification may be the main cause which lead the $\delta^{15} \mathrm{~N}$ values of QF being higher than that of YF. DNRA may be the main cause which lead the $\delta^{15} \mathrm{~N}$ values of organic nitrogen being higher than the values of inorganic nitrogen in fine-grained sedimentary rock. 